\title{
COMPARATIVE STUDY BETWEEN TRANSBRACHIAL VS TRANSFEMORAL ANGIOPLASTY OF CHRONIC COMPLETE ILIAC ARTERY OCCLUSION
}

\author{
By \\ Haytham Yousef Ali, Alaa El-Dein Sharaby and Mohamed Hamza \\ Department of Vascular Surgery, Faculty of Medicine, Al-Azhar University \\ Corresponding author: Haytham Yousef Ali, E-mail: hysamali4@gmail.com
}

\begin{abstract}
Background: Critical limb ischemia (CLI) is the most advanced stage of peripheral arterial occlusive disease; the prognosis is poor, with amputation rates up to $30 \%$ and mortality up to $25 \%$ after 1 year.

Objective: To compare between transbrachial approach and ipsilateral transfemoral approach either ultrasound guided or road map technique in common iliac artery occlusion angioplasty.

Patients and Methods: A retrospective study conducted at the Department of Vascular Surgery, Faculty of Medicine, Al-Azhar University Hospitals from January 2019 till October 2020. The 88 patients who are candidates for study were subdivided into to three groups: Group A: Including 31 patients for whom transbrachial iliac angioplasty, Group B: Including 30 patients for whom transfemoral ultrasound guided iliac angioplasty and Group C: Including 27 patients for whom transfemoral road map guided iliac angioplasty. All lesions were categorized according to the Trans-Atlantic Inter-Society Consensus II (TASC) classification.

Results: Transbrachial success rate was $90.32 \%$ compared with 96.6 in transfemoral access. No statistical difference was found. Patency rate reached $90.3 \%, 90.0 \%$ and $85.2 \%$ in transbrachial, transfemoral ultrasound and transfemoral road map guided groups respectively (X2:0.462; $\mathrm{P}=0.794)$. Peri-procedural complication rate reached $16.1 \%, 6.7 \%$ and $74.1 \%$ in Tran brachial, transfemoral ultrasound and transfemoral road map guided groups, respectively. Complications were statistically higher significantly in transfemoral road map guided group $(\mathrm{X} 2: 0.462 ; \mathrm{P}=0.794)$. Thirty days mortality rate reached $11.1 \%, 23.8 \%$ and $17.4 \%$ in Tran brachial, transfemoral ultrasound and transfemoral road map guided groups, respectively. This was not statistically different among the three access groups (X2: 1.362; $\mathrm{P}=0.506)$. Amputation rate reached $9.7 \%$, $6.7 \%$ and $3.7 \%$ in transbrachial, transfemoral ultrasound and transfemoral road map guided groups, respectively. No statistically significant difference was found (X2: 6.207; $\mathrm{P}=0.145)$.
\end{abstract}

Conclusion: The technical success of all approaches is high, with higher success rate in transfemoral access. While we found more bleeding complications with transfemoral access.

Keywords: Transbrachial, Ipsilateral, Transfemoral, Iliac, Angioplasty.

\section{INTRODUCTION}

Peripheral arterial disease (PAD) of the lower limbs is the third most important site of atherosclerotic disease alongside coronary heart disease (CHD) and cerebrovascular disease (CVD), This clinical condition has often been neglected in the past but, in the recent years, PAD has received growing attention as an important cause of disability and of cardiovascular morbidity and mortality (Novo et al., 2018). 
PAD is defined as a slowly progressing, occlusive vascular disease of the extremities primarily due to atherosclerosis which can involve vasculitis and thrombosis, The incidence of PAD is increasing worldwide due to an overall increase in diabetes, obesity, and other cardiovascular disorders (Norgren et al., 2014).

Critical limb ischemia (CLI) is the term used to delineate the condition in which arterial disease has resulted in pain in the foot even at the rest or in a breakdown of the skin (ulcer or gangrene) (Novo et al., 2018).

CLI is a condition in which patient presents with clinical status of pain at rest or has atrophic ulcers, and is a clinical presentation linked with a high risk of loss of the affected limb. In developed countries incidence is estimated at 50 to 100 cases in 100 thousand inhabitants per1 year (Moreira et al., 2018).

Patients with lower extremity ischemia are typically divided into two groups, those with intermittent claudication and those with CLI, depending on symptoms at presentation, Claudication and CLI are managed differently because of major differences in their natural histories and expected clinical outcomes after treatment (Muluk et al., 2011).

CLI is the most advanced stage of peripheral arterial occlusive disease, the prognosis is poor, with amputation rates up to $30 \%$ and mortality up to $25 \%$ after 1 year (Norgren et al., 2014).

CLI is therefore clearly responsible for increasing morbidity and mortality and consumes considerable social and healthcare resources, The ideal treatment for CLI is revascularization, which can be accomplished using conventional surgical techniques (bypass) or endovascular methods (angioplasty) (Moreira et al., 2018). The first reports of combined endovascular and open surgical procedures are from the 1970 (Aho and Venermo, 2017).

In hybrid reconstructions, patients are treated using both endovascular and open revascularization techniques simultaneously, most often at different levels. In recent years, these multilevel reconstructions have been used increasingly often, especially by vascular surgeons as they master both endovascular and open surgical skills, and as the endovascular techniques as such have evolved. Hybrid procedures offer a less invasive approach for patients with multiple co-morbidities and have recently been preferred whenever possible. Lower morbidity and mortality, as well as reduced stay in both hospital and intensive care are advantages with these minimally invasive techniques (Aho and Venermo, 2017).

The primary goals for the treatment of CLI are to relieve ischemic pain, heal neuro-ischemic ulcers, prevent limb loss, improve patient function and quality of life and prolong survival. To achieve these outcomes, most patients will ultimately need a revascularization procedure. For some CLI patients with severe comorbidities or a very limited chance of successful revascularization, a primary amputation may be the most appropriate treatment (Aboyans et al., 2017).

The aim of the present work was to compare between transbrachial approach and ipsilateral transfemoral approach 
either ultrasound guided or road map technique in common iliac artery occlusion angioplasty.

\section{PATIENTS AND METHODS}

This retrospective randomized study was performed in Al-Azhar university hospitals mainly from January 2019 till October 2020. The 88 patients who are candidates for study were subdivided into to three groups: Group A: Including 31 patients for whom transbrachial iliac angioplasty, Group B: Including 30 patients for whom transfemoral ultrasound guided iliac angioplasty and Group C: Including 27 patients for whom transfemoral road map guided iliac angioplasty.

All lesions were categorized according to the Trans-Atlantic Inter-Society Consensus II (TASC) classification.

Inclusion criteria were Critical ischaemia (persistent rest pain of more than two weeks duration or ulcers or tissue loss or gangrene of one or more toes or ankle brachial Pressure Index (ABPI) $<0.4$, or peak systolic velocity (PSV) $>$ $300 \mathrm{~cm}$ per sec) and Chronic ischaemia with disabling claudication pain interfering with patient's social activities after failed medical treatment.

Exclusion criteria were Acute Lower limb ischaemia, Distal superficial femoral artery lesion, Patients with chronic ischaemia improved with conservative treatment, and Renal failure patient.

Full history was taken and Clinical examination. Investigations included Laboratory investigations and Radiological investigations including Duplex examination of the lower limb arteries, CT angiography or MRA. All patients were screened for cerebrovascular disease, as well as patency of the access vessel and the subclavian artery, prior to a transbrachial intervention. (3) Other investigations: as E.C.G.

Follow up was carried out immediately in the vascular surgery department up to 12 months after the intervention in vascular outpatient clinic, regarding the followings points: Hemodynamic state (ABPI, and pulse wave recordings), Limb salvage rate (The need for major amputation), Assessment of patency: by duplex scan, and Assessment of patency by CT angiography (in selected cases). Permission from Al-Azharf faculty of medicine ethical committee was also obtained and approval from institutional review board was taken.

\section{Statistical analysis:}

Data were verified, coded by the researcher and analyzed using IBM-SPSS Statistics for windows, version 23.0 (Copyright IBM Corp., Armonk, N.Y., USA. 2015). Descriptive statistics: Means, standard deviations, medians, ranges and percentages were calculated. Test of significances: chi-square test was used to compare the difference in distribution of frequencies among different groups. For continuous variables; independent t-test analysis was carried out to compare the means of dichotomous data. There was no specific calculation of the sample size. A significant $\mathrm{p}$-value was considered when it was equal or less than 0.05 . 


\section{RESULTS}

Regarding age and gender distribution, no statistical difference was found $(\mathrm{p}=0.794), \quad(\mathrm{p}=0.217)$ respectively. No statistical difference was found in $\mathrm{Hb}$, creatine. no INR levels preoperatively ( $>0.05$ ), while mean TLC and platelets were significantly lower in trans brachial group $(\mathrm{P}<0.001)$. This difference was not clinically important as all values were within the normal TLC and PLT ranges. Regarding comorbidities, smoking, D.M., HTN, IHD and Dyslipidemia showed no statistically significant difference among the three groups ( $p>0.05)$ (Table 1).

Table (1): Demographic characteristics and associated comorbidities

\begin{tabular}{|c|c|c|c|c|c|c|c|c|}
\hline \multirow{2}{*}{\multicolumn{2}{|c|}{$\begin{array}{ll}\text { Parameters } & \text { Groups } \\
\text { Age (Mean, SD) } \\
\end{array}$}} & \multicolumn{2}{|c|}{$\begin{array}{c}\text { Transbrachial } \\
\quad \mathbf{N}=\mathbf{3 1}\end{array}$} & \multicolumn{2}{|c|}{$\begin{array}{c}\text { Transfemoral } \\
\text { ultrasound } \\
\mathbf{N}=\mathbf{3 0} \\
\end{array}$} & \multicolumn{2}{|c|}{$\begin{array}{c}\text { Transfemoral } \\
\text { road map } \\
\mathbf{N}=27\end{array}$} & \multirow{2}{*}{$\begin{array}{c}\mathbf{P} \\
>0.05\end{array}$} \\
\hline & & 62.61 & 7.00 & 63.40 & 8.92 & 61.56 & 14.04 & \\
\hline \multirow{2}{*}{$\operatorname{Sex}(N, \%)$} & Male & 21 & $67.7 \%$ & 20 & $66.7 \%$ & 23 & $85.2 \%$ & \multirow{2}{*}{$>0.05$} \\
\hline & Female & 10 & $32.3 \%$ & 10 & $33.3 \%$ & 4 & $14.8 \%$ & \\
\hline \multirow{5}{*}{ Lab } & HB & 13.45 & 1.75 & 13.00 & 1.88 & 13.56 & 2.28 & $>0.05$ \\
\hline & TLC & 6.02 & 1.30 & 11.73 & 6.07 & 10.78 & 7.58 & $>0.05$ \\
\hline & PLT & 267.90 & 86.95 & 326.83 & 78.35 & 341.85 & 130.12 & $>0.05$ \\
\hline & CREAT & 0.99 & 0.11 & 1.07 & 0.19 & 1.01 & 0.04 & $>0.05$ \\
\hline & INR & 1.05 & 0.09 & 0.98 & 0.05 & 0.99 & 0.04 & $>0.05$ \\
\hline \multirow{2}{*}{ Smoking } & No & 12 & $38.7 \%$ & 13 & $43.3 \%$ & 8 & $29.6 \%$ & \multirow{2}{*}{$>0.05$} \\
\hline & Yes & 19 & $61.3 \%$ & 17 & $56.7 \%$ & 19 & $70.4 \%$ & \\
\hline \multirow{2}{*}{ D.M. } & No & 8 & $25.8 \%$ & 8 & $26.7 \%$ & 11 & $40.7 \%$ & \multirow{2}{*}{$>0.05$} \\
\hline & Yes & 23 & $74.2 \%$ & 22 & $73.3 \%$ & 16 & $59.3 \%$ & \\
\hline \multirow{2}{*}{ HTN } & No & 9 & $29.0 \%$ & 8 & $26.7 \%$ & 7 & $25.9 \%$ & \multirow{2}{*}{$>0.05$} \\
\hline & Yes & 22 & $71.0 \%$ & 22 & $73.3 \%$ & 20 & $74.1 \%$ & \\
\hline \multirow{2}{*}{ IHD } & No & 14 & $45.2 \%$ & 12 & $40.0 \%$ & 11 & $40.7 \%$ & \multirow{2}{*}{$>0.05$} \\
\hline & Yes & 17 & $54.8 \%$ & 18 & $60.0 \%$ & 16 & $59.3 \%$ & \\
\hline \multirow{2}{*}{ Dyslipidemia } & No & 8 & $25.8 \%$ & 10 & $33.3 \%$ & 6 & $22.2 \%$ & \multirow{2}{*}{$>0.05$} \\
\hline & Yes & 23 & $74.2 \%$ & 20 & $66.7 \%$ & 21 & $77.8 \%$ & \\
\hline \multirow{2}{*}{ Previous Angio } & No & 25 & $80.6 \%$ & 21 & $70.0 \%$ & 23 & $85.2 \%$ & \multirow{2}{*}{$>0.05$} \\
\hline & Yes & 6 & $19.4 \%$ & 9 & $30.0 \%$ & 4 & $14.8 \%$ & \\
\hline
\end{tabular}

Gangrene was the most frequent lesion of patients in all groups. Chi square test revealed significant difference between groups regarding preoperative lesion or rest pain $(\mathrm{P}=0.002)$. Rutherford classifications of arterial lesions were equally distributed among the three groups of the study. We have divided patients into two main categories of II, III and IV, V groups (Table 2).

Table (2): Clinical findings and Rutherford Classification

\begin{tabular}{|c|c|c|c|c|c|c|c|c|}
\hline \multicolumn{2}{|c|}{ Lesions $\quad$ Groups } & \multicolumn{2}{|c|}{ Transbrachial } & \multicolumn{2}{|c|}{$\begin{array}{c}\text { Transfemoral } \\
\text { US }\end{array}$} & \multicolumn{2}{|c|}{$\begin{array}{l}\text { Transfemoral } \\
\text { road map }\end{array}$} & $\mathbf{P}$ \\
\hline Rest pa & & 7 & $22.6 \%$ & 3 & $10.0 \%$ & 0 & $0.0 \%$ & \multirow{3}{*}{0.002} \\
\hline \multirow{2}{*}{\multicolumn{2}{|c|}{$\begin{array}{c}\text { Ulcer } \\
\text { Gangrene }\end{array}$}} & 4 & $12.9 \%$ & 0 & $0.0 \%$ & 8 & $29.6 \%$ & \\
\hline & & 20 & $64.5 \%$ & 27 & $90.0 \%$ & 19 & $70.4 \%$ & \\
\hline Rutherford & II, III & 21 & $67.7 \%$ & 20 & $66.7 \%$ & 18 & $66.7 \%$ & \multirow[b]{2}{*}{$>0.05$} \\
\hline Classification & IV, V & 10 & $32.3 \%$ & 10 & $33.3 \%$ & 9 & $33.3 \%$ & \\
\hline
\end{tabular}


Duration of the procedure was measured from time of anesthesia to the retrieval of all endovascular set. By running one-way ANOVA test, no difference was found between the three interventions ( $\mathrm{F}: 1.666 ; \mathrm{p}=0.195)$. Also, hospital stay time was measured from time of admission to the postoperative discharge. By running one-way ANOVA test, no difference was found between the three interventions ( $\mathrm{F}: 1.766 ; \mathrm{p}=0.177)$. Also, Fluoroscopic time and Contrast dose both show no significant difference between all three access groups $(\mathrm{P}>0.05)$ (Table 3).

Table (3): Operative details

\begin{tabular}{|c|c|c|c|c|c|c|c|}
\hline Groups & \multicolumn{2}{|c|}{ Transbrachial } & \multicolumn{2}{c|}{$\begin{array}{c}\text { Transfemoral } \\
\text { ultrasound }\end{array}$} & \multicolumn{2}{c|}{$\begin{array}{c}\text { Transfemoral } \\
\text { road map }\end{array}$} & \multirow{2}{*}{ P } \\
\cline { 2 - 8 } Parameters & Mean & SD & Mean & SD & Mean & SD & \\
\hline $\begin{array}{c}\text { Procedure time } \\
\text { (hours) }\end{array}$ & 1.45 & 0.39 & 1.65 & 0.56 & 1.48 & 0.38 & 0.195 \\
\hline Hospital stay (hours) & 25.55 & 13.41 & 27.60 & 17.01 & 35.11 & 28.23 & 0.177 \\
\hline $\begin{array}{c}\text { Fluoroscopic time, } \\
\text { min }\end{array}$ & 11.7 & 6.2 & 13.1 & 4.3 & 16.4 & 8.6 & 0.14 \\
\hline Contrast dose, ml & 97.7 & 78.3 & 99.3 & 45.8 & 102.1 & 65.3 & 0.75 \\
\hline
\end{tabular}

Local anesthesia with or without IV sedation was the most frequent method in all interventions. Spinal anesthesia was used in $2(6.7 \%)$ and $4(14.8 \%)$ of Transfemoral ultrasound and Transfemoral road map guided groups respectively. This difference was statistically significant $(\mathrm{P}=0.083)$. Interventions included balloon dilatation with or without stenting was not statistically different in all groups $(\mathrm{p}=0.066)$. Transbrachial success rate was $90.32 \%$ compared with 96.6 in transfemoral access. While transfemoral access showed mathematically higher success rate than transbrachial access, there was not statistically different between all access groups (Table 4).

Table (4): Angio plastic Intervention and success rate

\begin{tabular}{|l|l|c|c|c|c|c|c|c|}
\hline \multirow{2}{*}{ Parameters } & Groups & \multicolumn{2}{|c|}{ Transbrachial } & \multicolumn{2}{|c|}{$\begin{array}{c}\text { Transfemoral } \\
\text { US }\end{array}$} & \multicolumn{2}{c|}{$\begin{array}{c}\text { Transfemoral } \\
\text { road map }\end{array}$} & \multirow{2}{*}{ P } \\
\hline Intervention & Balloon & 22 & $71.0 \%$ & 21 & $70.0 \%$ & 12 & $44.4 \%$ & \multirow{2}{*}{0.066} \\
\cline { 2 - 9 } & $\begin{array}{l}\text { Balloon } \\
\text { and stent }\end{array}$ & 9 & $29.0 \%$ & 9 & $30.0 \%$ & 15 & $55.6 \%$ & \\
\hline \multicolumn{2}{|l|}{ Technical success } & 28 & $90.32 \%$ & 29 & $96.66 \%$ & 26 & $96.30 \%$ & 0.154 \\
\hline
\end{tabular}

Patency rate reached $90.3 \%, 90.0 \%$ and $85.2 \%$ in Tran brachial, Transfemoral ultrasound and Transfemoral road map guided groups respectively 1-month post operatively. This distribution was near equal (X2:0.462; $\mathrm{P}=0.794)$. In the following 12 months these percentages decreased in all access groups. All interventions lead to a significant improvement of ABI postoperatively. Wilcoxon signed rank test revealed a statistically higher post-operative ABI than preoperatively $(\mathrm{p}<0.001)$ (Table 5). 
Table (5): Technical success

\begin{tabular}{|c|c|c|c|c|c|c|c|c|}
\hline \multicolumn{2}{|c|}{ Parameters } & \multicolumn{2}{|c|}{$\begin{array}{l}\text { Transbrachia } \\
\qquad \mathbf{l}(\mathbf{n}=\mathbf{3 1})\end{array}$} & \multicolumn{2}{|c|}{$\begin{array}{c}\text { Transfemoral } \\
\text { ultrasound } \\
(\mathbf{n}=\mathbf{3 0})\end{array}$} & \multicolumn{2}{|c|}{$\begin{array}{l}\text { Transfemoral } \\
\text { road map } \\
(\mathbf{n}=27)\end{array}$} & $\mathbf{p}$ \\
\hline \multirow{2}{*}{$\begin{array}{c}\text { Presence of } \\
\text { complications }\end{array}$} & No & 26 & $83.9 \%$ & 28 & $93.3 \%$ & 7 & $25.9 \%$ & \multirow{2}{*}{$<0.001$} \\
\hline & Yes & 5 & $16.1 \%$ & 2 & $6.7 \%$ & 20 & $74.1 \%$ & \\
\hline \multirow{4}{*}{ Complications } & No & 26 & $83.9 \%$ & 28 & $93.3 \%$ & 7 & $25.9 \%$ & \multirow{4}{*}{$<0.001$} \\
\hline & Hematoma & 4 & $12.9 \%$ & 2 & $6.7 \%$ & 8 & $29.6 \%$ & \\
\hline & Ecchymosis & 1 & $3.2 \%$ & 0 & $0.0 \%$ & 4 & $14.8 \%$ & \\
\hline & $\begin{array}{l}\text { Retroperitone } \\
\text { al hematoma }\end{array}$ & 0 & $0.0 \%$ & 0 & $0.0 \%$ & 8 & $29.6 \%$ & \\
\hline \multirow{2}{*}{$\begin{array}{l}30 \text { days } \\
\text { mortality }\end{array}$} & No & 24 & $88.9 \%$ & 16 & $76.2 \%$ & 19 & $82.6 \%$ & \multirow[t]{2}{*}{$>0.05$} \\
\hline & Yes & 3 & $11.1 \%$ & 5 & $23.8 \%$ & 4 & $17.4 \%$ & \\
\hline \multirow[t]{2}{*}{ Amputation } & No & 28 & $90.3 \%$ & 28 & $93.33 \%$ & 26 & $96.30 \%$ & \multirow[t]{2}{*}{$>0.05$} \\
\hline & Amputated & 3 & $9.7 \%$ & 2 & $6.67 \%$ & 1 & $3.70 \%$ & \\
\hline
\end{tabular}

Peri-procedural complication rate reached $16.1 \%, 6.7 \%$ and $74.1 \%$ in Tran brachial, Transfemoral ultrasound and Transfemoral road map guided groups, respectively. Complications were statistically higher significantly in Transfemoral road map guided group (X2:0.462; $\mathrm{P}=0.794)$ (Table 5). 30 days mortality rate reached $11.1 \%, 23.8 \%$ and $17.4 \%$ in Tran brachial, Transfemoral ultrasound and Transfemoral road map guided groups, respectively. This was not statistically different among the three access groups (X2: 1.362; $\quad \mathrm{P}=0.506)$ (Table 6).

Amputation rate reached 9.7\%, 6.7\% and $3.7 \%$ in Tran brachial, Transfemoral ultrasound and Transfemoral road map guided groups, respectively. No statistically significant difference was found (X2: 6.207; $\mathrm{P}=0.145$ ) (Tables 5, 6).

All interventions lead to a significant improvement of ABI postoperatively. Wilcoxon signed rank test revealed a statistically higher post-operative ABI than preoperatively $(\mathrm{p}<0.001)$ with no difference between any of access groups at any point of follow up. Amputation rate reached $9.7 \%, 6.7 \%$ and $3.7 \%$ in Tran brachial, Transfemoral ultrasound and Transfemoral road map guided groups, respectively on three months postoperatively. (X2: $6.207 ; \quad \mathrm{P}=0.145)$ (Table 6).

\section{Table (6): 12 months follow up}

\begin{tabular}{|c|c|c|c|c|c|c|c|c|}
\hline \multirow{2}{*}{\multicolumn{2}{|c|}{ ABPI }} & \multicolumn{2}{|c|}{ Transbrachial } & \multicolumn{2}{|c|}{$\begin{array}{c}\text { Transfemoral } \\
\text { ultrasound }\end{array}$} & \multicolumn{2}{|c|}{$\begin{array}{c}\text { Transfemoral } \\
\text { road map }\end{array}$} & \multirow[t]{2}{*}{$\mathbf{P}$} \\
\hline & & Mean & SD & Mean & SD & Mean & SD & \\
\hline \multicolumn{2}{|c|}{ Pre } & 0.35 & 0.06 & 0.37 & 0.05 & 0.37 & 0.06 & $>0.05$ \\
\hline \multicolumn{2}{|l|}{ Post } & 0.87 & 0.08 & 0.85 & 0.09 & 0.86 & 0.05 & $>0.05$ \\
\hline \multicolumn{2}{|l|}{3 months } & 0.73 & 0.19 & 0.76 & 0.14 & 0.70 & 0.22 & $>0.05$ \\
\hline \multicolumn{2}{|c|}{12 months } & 0.75 & 0.18 & 0.72 & 0.15 & 0.78 & 0.13 & $>0.05$ \\
\hline \multirow{3}{*}{$\begin{array}{l}\text { Amputat } \\
\text { ion rate }\end{array}$} & 3 months & 3 & $9.7 \%$ & 2 & $6.67 \%$ & 1 & $3.70 \%$ & $>0.05$ \\
\hline & 6 months & 4 & $12.9 \%$ & 3 & $10 \%$ & 2 & $7.41 \%$ & $>0.05$ \\
\hline & 12 months & 6 & 19.35 & 7 & $23.3 \%$ & 5 & $18.52 \%$ & $>0.05$ \\
\hline \multirow{3}{*}{$\begin{array}{l}\text { Patency } \\
\text { rate }\end{array}$} & Post & 28 & $90.3 \%$ & 27 & $90.0 \%$ & 23 & $85.2 \%$ & $>0.05$ \\
\hline & 6 months & 25 & $80.65 \%$ & 24 & $80 \%$ & 19 & $70.37 \%$ & $>0.05$ \\
\hline & 12 months & 19 & $61.29 \%$ & 20 & $66.7 \%$ & 16 & $59.26 \%$ & $>0.05$ \\
\hline
\end{tabular}




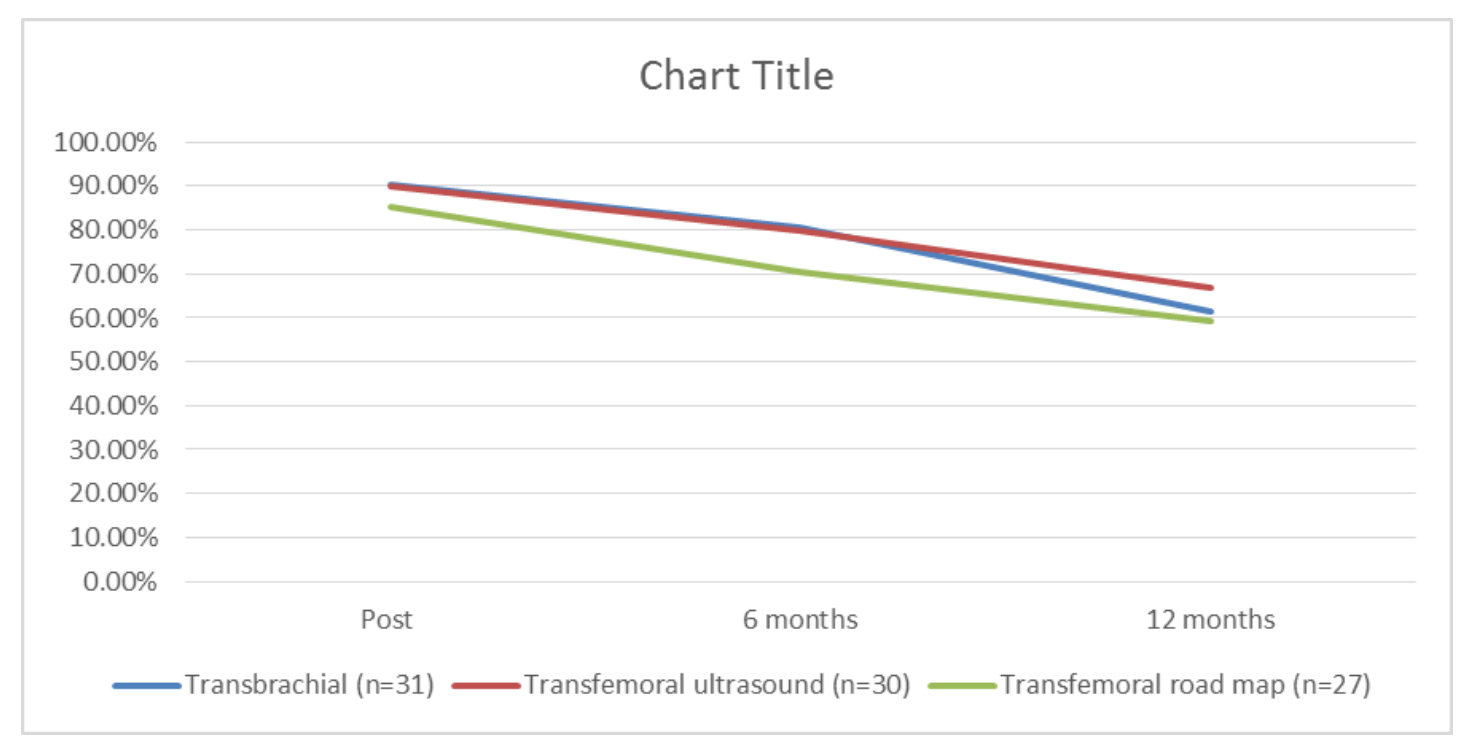

Figure (1): Patency rate

\section{DISCUSSION}

Percutaneous interventions are the preferred route of treatment of iliac stenotic atherosclerotic disease, to this day. In most cases, a transfemoral or transbrachial approach is the access site chosen for intervention. However, this route has not yet been validated for interventions of the peripheral tree. We here report the results of our experience with the brachial access for iliac angioplasty. The aim of this study was to compare transbrachial approach and ipsilateral transfemoral approach either ultrasound guided or road map technique in common iliac artery occlusion angioplasty, as regard to applicability, effectiveness, patency rate as well as complications (Coroleu et al., 2018).

In this study, regarding age and gender distribution, no statistical difference was found $(p>0.05)$. Preoperative laboratory investigations showed no statistical difference regarding $\mathrm{Hb}$, creatinine, and INR levels. Regarding comorbidities, Smoking, D.M., HTN, IHD and Dyslipidemia showed no statistically significant difference among the three groups Rutherford classifications of arterial lesions were equally distributed among the three groups of the study. We have divided patients into two main categories, II, III and IV, V groups. This was matched with a study by Cortese et al. (2017) evaluating transradial compared with transfemoral access in treating iliac occlusive disease.

In this study, fluoroscopic time, and contrast dose both show no significant difference between all three access groups. Duration of the procedure was measured from time of anesthesia to the retrieval of all endovascular set. By running one-way ANOVA test, no difference was found between the three interventions. This was in agreement with Cortese et al. (2017) reporting that mean duration of intervention and fluoroscopy time in the radial group were as low as in the femoral group, reflecting how the longer path that the devices have to undertake to reach the culprit lesion is not associated with an increase in the complexity of the intervention. 
In our study, transbrachial success rate was $90.32 \%$ compared with 96.6 in transfemoral access. This was not statistically different in all access groups. While transfemoral access showed mathematically higher success rate than transbrachial access. This was matched with Turner et al. (2017) showing that access does not influence success rate significantly. They interpreted that by the ability of the guidewire to cross the lesion, even in case of total occlusion, was not influenced by the access route. Also, the primary technical success rate in Stavroulakis et al. (2016) which was $81 \%$ owing to $11 \%$ technical failures requiring an additional transfemoral access to restore iliac artery patency.

Thus, they recommended transbrachial approach only in cases where the transfemoral approach is challenging or not applicable, such as (1) severely obese patients, (2) patients with groin infections in urgent need of therapy (critical limb ischemia), (3) previous endovascular or open aortic reconstructions having neobifurcations unsuitable for a contralateral femoral approach, and (4) a variety of lesions that can make the inguinal approach challenging. The brachial approach has been used increasingly in endovascular therapy of various vascular territories (Treitl et al., 2015).

However, these studies included multiple vascular pathologies (e.g., mesenteric disease, peripheral artery disease, thoracoabdominal aneurysms), which compromise the evaluation of this approach. Moreover, in many series, brachial artery catheterization was complimentary to transfemoral access or followed its failure. Thus, the efficiency of primary brachial artery access has been inadequately evaluated in these studies. Our study divided patients into separate groups to evaluate transbrachial access compared to transfemoral access. In a study by Basche et al. (2019), brachial artery access enabled endovascular treatment of most iliac lesions via a single vessel access. Although it has been suggested that long peripheral obstructions are very difficult to cross in the transbrachial setting.

They reported that the treatment of TASC II C/D lesions did not influence technical success rate. Because of the unique anatomic characteristics of iliac vessels, a dual arterial access approach can often be required, not only in cases of primary brachial artery access but also when a transfemoral access is the first choice, especially for the treatment of extensive disease (Mirza et al., 2014).

In our study, patency rate reached $90.3 \%, 90.0 \%$ and $85.2 \%$ in Tran brachial, Transfemoral ultrasound and Transfemoral road map guided groups respectively. This distribution was near equal. All interventions lead to a significant improvement of ABI postoperatively. Wilcoxon signed rank test revealed a statistically higher postoperative ABI than preoperatively. 30 days mortality rate reached $11.1 \%, 23.8 \%$ and $17.4 \%$ in Tran brachial, Transfemoral ultrasound and Transfemoral road map guided groups, respectively. This was not statistically different among the three access groups.

Peri-procedural complication rate in this study reached $16.1 \%, 6.7 \%$ and $74.1 \%$ in Tran brachial, Transfemoral 
ultrasound and Transfemoral road map guided groups, respectively. Hematoma formation was statistically higher significantly in Transfemoral group. These findings agree with Ichihashi et al. (2017) which reported that transfemoral access was associated with a considerable rate of local bleeding complications that result increased with larger sheaths. Thus, successful interventions are sometimes hampered by procedural-related complications. The transbrachial access has often been shown to reduce the risk of local complications after coronary interventions.

Several studies have shown the same point how radial approach warrants significantly lower all-types of access site bleedings, and the association between severe bleedings and death has been widely demonstrated (Joyal et al., 2018). Continuously growing experience and technological improvements, achieved also thanks to a big environment by manufacturers, have totally covered the early technical gaps with the transfemoral route, thus resulting in the chance of treating substantially all the pathologies of the coronary tree (Hamon et al., 2018).

Cortese et al. (2017) reported that the peripheral application of transradial approach has the advantage of reducing entry site bleeding complications especially with usage of small sheaths. Other authors have previously reported of iliac interventions performed via the radial access, but a feasibility study and a comparison with the transfemoral route have not yet been reported (Sanghvi et al., 2018).

Our complication rate was comparable to other reported series Alvarez-Tostado et al. (2019). So, it seems that this event is procedure related and not physician dependent.

Local hematomas and pseudoaneurysms dominated, while the incidences of major puncture site complications such as thrombotic occlusion or bleeding were relatively low. Interestingly, as already reported by Alvarez-Tostado et al. (2019) sheath size did not influence the access site complication rate, but $>6-\mathrm{F}$ sheaths were not routinely used (a 7-F sheath was used in only 3 patients).

\section{CONCLUSION}

The technical success of the three approaches is high, with higher success rate in transfemoral access in treating iliac occlusive disease. While we found more bleeding complications with transfemoral access.

Conflicts of interest: No conflicts of interest were found.

\section{REFERENCES}

1. Aboyans V, Ricco JB, Bartelink MEL, Björck M, Brodmann M, Cohnert T, Collet JP, Czerny M, De Carlo M, Debus S, Espinola-Klein C, Kahan T, Kownator S, Mazzolai L, Naylor AR, Roffi M, Röther J and Sprynger M. (2017): ESC Guidelines on the Diagnosis and Treatment of Peripheral Arterial Diseases, in collaboration with the European Society for Vascular Surgery (ESVS) Vascular Surgery (ESVS). European Heart Journal, 39(9): 763-816.

2. Aho PS and Venermo M. (2017): Hybrid Procedures as a Novel Technique in the Treatment of Critical Limb Ischemia. Scandinavian Journal of Surgery, 101(2): 107113.

3. Alvarez-Tostado JA, Moise MA, James F and Bena F. (2019): The brachial artery: A 
critical access for endovascular procedures. Journal of Vascular Surgery, 49(2): 378-385.

4. Basche $S$, Eger $C$ and Aschenbach $R$ (2019): The brachial artery as approach for catheter interventions - indications, results, complications. Vasa, 33(4): 235-238.

5. Coroleu SF, Burzotta $F$ and FernándezGómez C. (2018): Feasibility of complex coronary and peripheral interventions by trans-radial approach using large sheaths. Catheter Cardiovasc Interv., 79(4):597-600.

6. Cortese B, Peretti E, Troisi N, Siquilberti E, Setti $M$ and Pitì A. (2017): Transradial percutaneous iliac intervention, a feasible alternative to the transfemoral route. Cardiovascular Revascularization Medicine, 13(6): 331-334.

7. Hamon M, Mehta S, Steg PG, Faxon D, Kerkar P, Rupprecht HJ, Tanguay JF, Afzal R and Yusuf S. (2018): Impact of transradial and transfemoral coronary interventions on bleeding and net adverse clinical events in acute coronary syndromes. EuroIntervention, 7(1): 91-97.

8. Ichihashi S, Higashiura $\mathbf{W}$, Itoh $\mathbf{H}$, Sakaguchi S, Nishimine $\mathrm{K}$ and Kichikawa K. (2017): Long-term outcomes for systematic primary stent placement in complex iliac artery occlusive disease classified according to Trans-Atlantic InterSociety Consensus (TASC)-II. Journal of Vascular Surgery, 53(4): 992-999.

9. Joyal D, Bertrand OF, Rinfret S, Shimony A and Eisenberg MJ. (2018): Meta-Analysis of Ten Trials on the Effectiveness of the Radial Versus the Femoral Approach in Primary Percutaneous Coronary Intervention. The American Journal of Cardiology, 109(6): 813-818.

10. Mirza AK, Steerman SN and Ahanchi S. (2014): Analysis of vas-cular closure devices after transbrachial artery access. Vasc Endovascular Surg., 48:466-469.

11. Moreira RW, Costa PV and Carrilho DDR. (2018): Treatment of critical lower limb ischemia using a hybrid technique. Jornal Vascular Brasileiro, 13(3): 257-261.

12. Muluk SC, Muluk VS and Kelley ME (2011): Outcome events in patients with claudication: a 15 -year study in 2777 patients. J Vasc Surg., 33:251-257.

13. Norgren L, Hiatt W, Dormandy J, Nehler M, Harris $K$ and Fowkes F (2014): Inter Society Consensus for the Management of Peripheral Arterial Disease (TASC II). Eur J Vasc Endovasc Surg., 33:1-75.

14. Novo S, Coppola G and Milio G. (2018): Critical Limb Ischemia: Definition and Natural History. Current Drug Target Cardiovascular \& Hematological Disorders, 4(3): 219-225.

15. Sanghvi K, Kurian $D$ and Coppola J. (2018): Transradial Intervention of Iliac and Superficial Femoral Artery Disease is Feasible. Journal of Interventional Cardiology, 21(5): 385-387.

16. Stavroulakis K, Usai MV, Torsello G, Schwindt A, Stachmann A, Beropoulis E and Bisdas T. (2016): Efficacy and safety of transbrachial access for iliac endovascular interventions. Journal of Endovascular Therapy, 23(3): 454-460.

17. Treitl KM, König C and Reiser MF. (2015): Complications of transbrachial arterial access for peripheral endovascular interventions. $\mathbf{J}$ Endovasc Ther., 22:63-70.

18. Turner S, Sacrinty M, Manogue M, Little W, Gandhi S and Kutcher M. (2017): Transitioning to the radial artery as the preferred access site for cardiac catheterization: an academic medical center experience. Catheter Cardiovasc Interv., 80(2):247-57. 


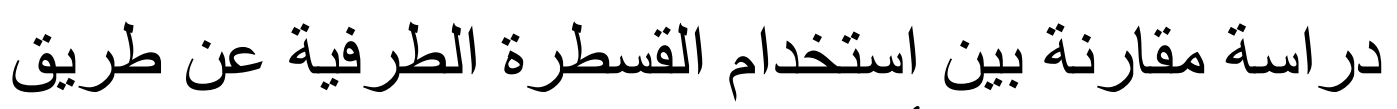

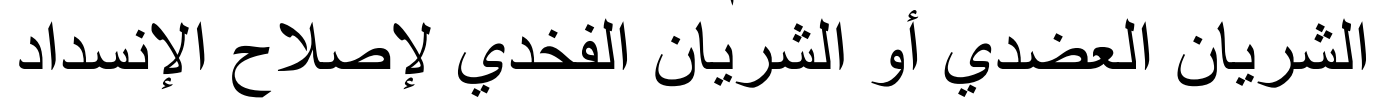

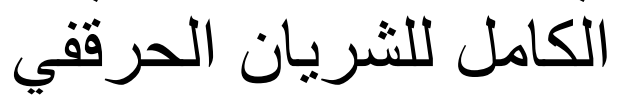

هيثم يوسف علي أحمد إبراهيم أبو السعد، علاء الدين مصطفي كمال شرابي، محمد حمزة حامد

قسم جراحة الأوعية الدموية، كلية الطب، جامعة الأزهر

E-mail: hysamali4@gmail.com

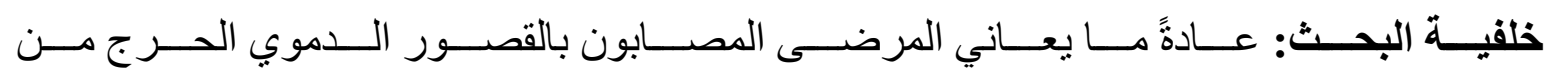

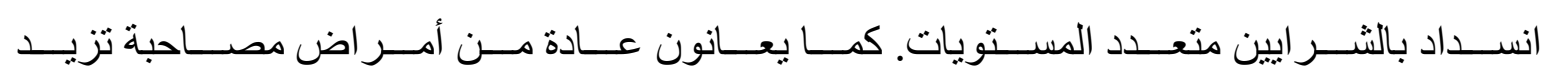

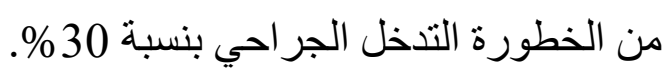

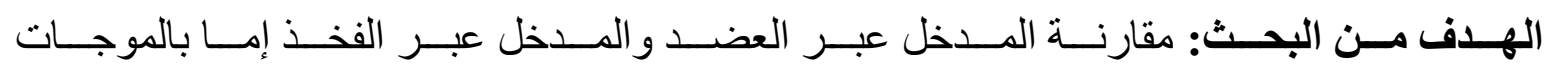

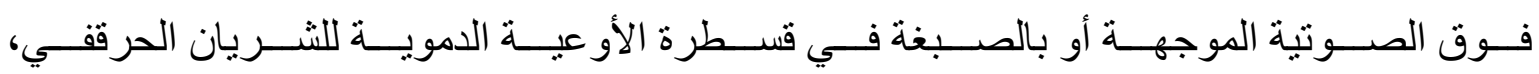
فيما يتعلق بالتطبيق و الفعالية وكذللك المضاعفات.

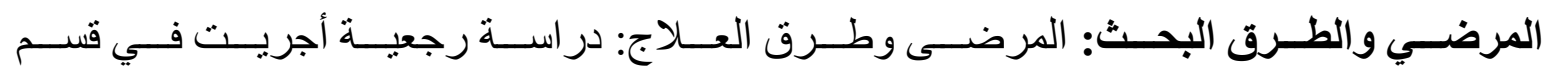

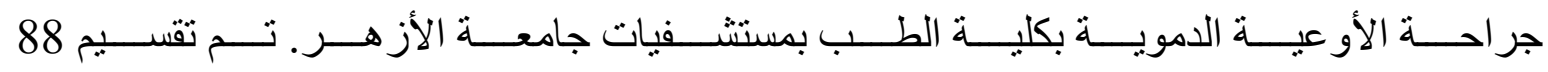

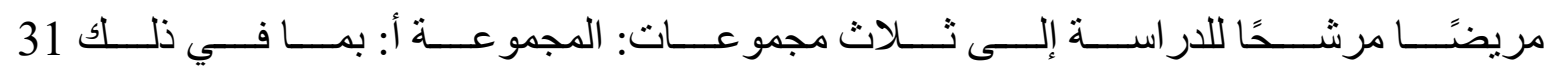

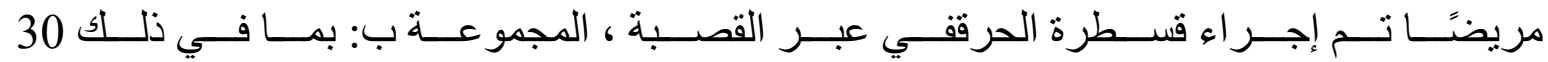

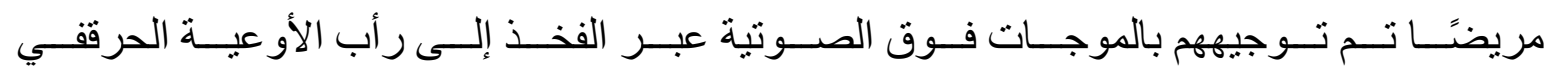

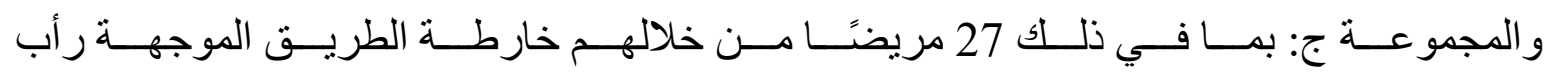
الأو عية الدموية الحرقفي.

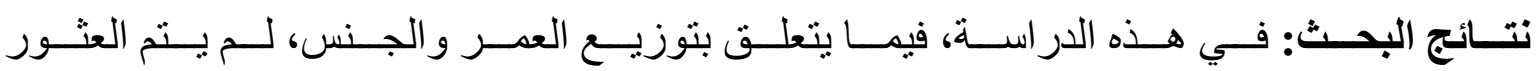

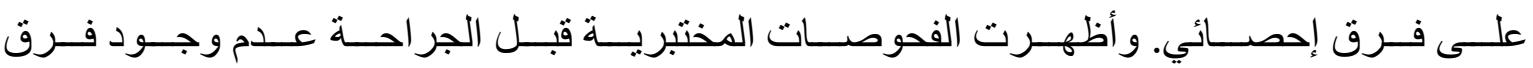

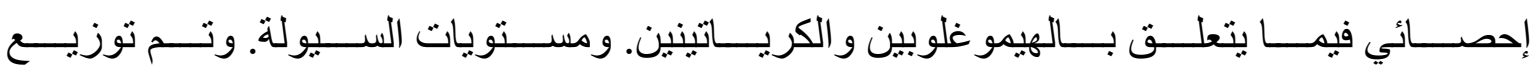
تصنيف رذرفورد للانسداد الثرياني بالتساوي بين المجمو عات الثناث للار اسة. 


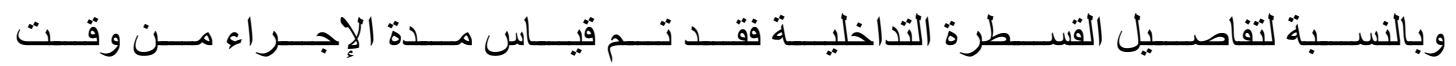

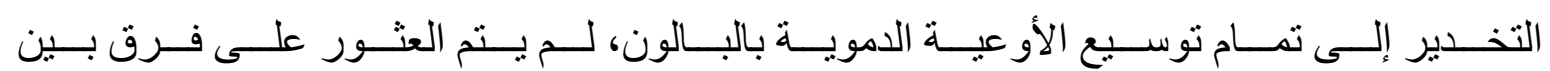

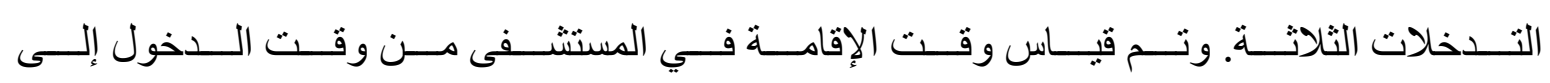

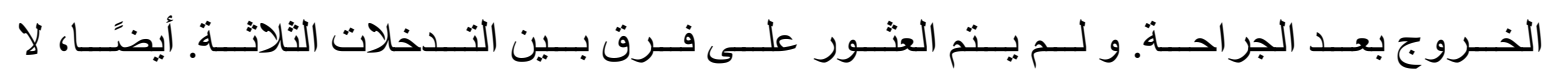

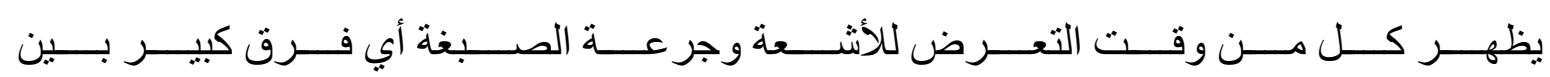

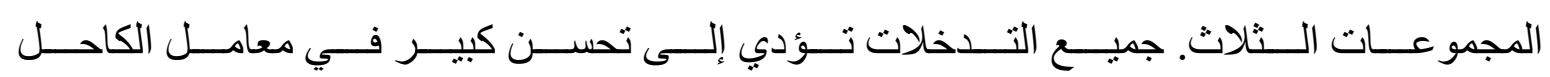

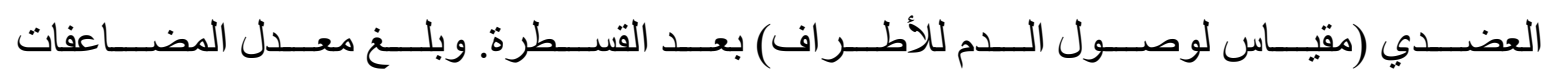

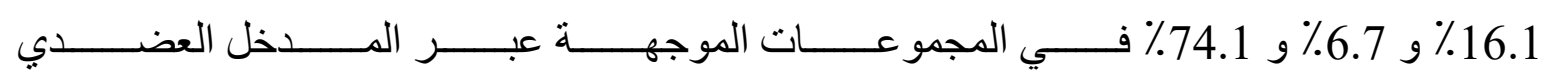

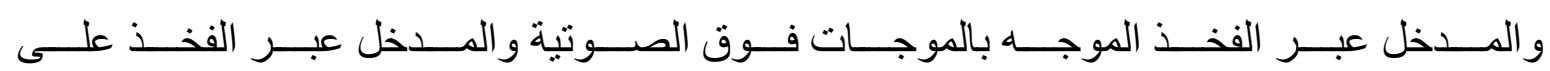

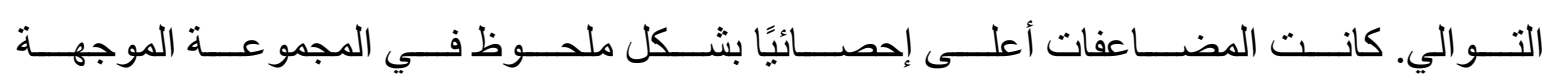
بدون موجات فوق صوتية عبر الفخذ.

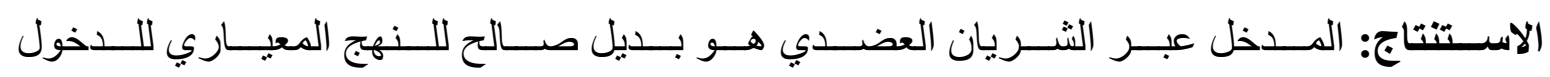

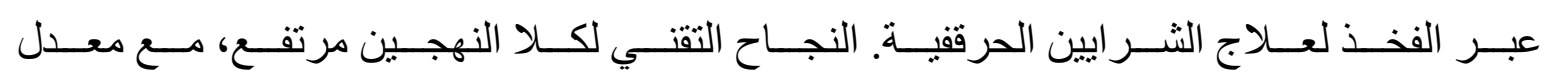

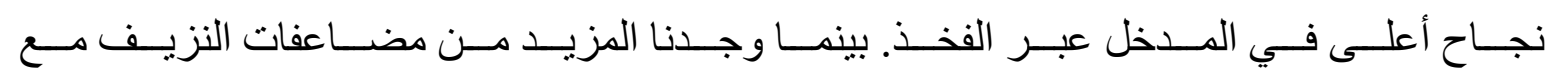
المدخل عبر الفخذ.

الكلمات الدالة: القسطرة، القسطرة الطرفية، الحرقفي. 